\title{
High Efficiency Operation of a Switched Reluctance Generator over a Wide Speed Range
}

\author{
Siyang $\mathrm{Yu}^{*}$, Fengge Zhang ${ }^{*}$, Dong-Hee Lee ${ }^{* *}$, and Jin-Woo Ahn ${ }^{\dagger}$ \\ *School of Electrical Engineering, Shenyang University of Technology, Shenyang, China \\ ${ }^{* * \dagger}$ Department of Mechatronics Engineering, Kyungsung University, Busan, Korea
}

\begin{abstract}
This paper investigates the high efficiency operation of a switched reluctance generator over a wide speed range. The system efficiency is improved by optimizing the current shape. A modified angle position control (MAPC) method that can be used to optimize the current shape over a wide speed range is proposed. Simulation and experimental results are presented to validate the effectiveness of the proposed control scheme.
\end{abstract}

Key words: Core loss calculation, High-efficiency operation, Switched reluctance generator, Variable-speed

\section{INTRODUCTION}

There are a lot of advantages to a switched reluctance generator (SRG). The rotor construction is very simple, because it consists of only laminated steel. The stator part consists of concentrated phase windings mounted on salient poles [1]. This is good in a commercial sense, since the manufacturing cost is low [2]. In addition, the absence of windings and permanent magnets on the rotor encourages high speed and temperature operation [3]. Furthermore, all of the phases of an SRG are electrically and magnetically independent from each other, which results in improved system reliability [4], [5]. The merits of SRGs have been demonstrated for some applications such as starter/generators for the gas turbines of aircraft [6], windmill generators [7] and alternators for automotive applications [8]. The objective of SRG control is normally to track the output power and to keep the DC-link voltage at a desired value with a high efficiency, low torque ripple, and low acoustic noise. These control objectives can be optimized by appropriately adjusting the turn on/off angles and other parameters.

At present, there is little relevant literature on improving the system efficiency of SRGs, especially those that are operated

Manuscript received Dec. 27, 2013; accepted Aug. 18, 2014

Recommended for publication by Associate Editor Sanjib K. Panda.

${ }^{\dagger}$ Corresponding Author: jwahn@ks.ac.kr

Tel: +82- 51-663-4773, Fax: +82- 51-624-5980, Kyungsung University

"School of Electrical Eng., Shenyang University of Technology, China

"** Dept. of Mechatronics Eng., Kyungsung University, Korea over a wide speed range. In [9], for the whole spectrum of operating speeds, all of the possible turn-on and conduction angles have been simulated to get a desired power factor. In other words, the copper losses have been minimized and the efficiency has been improved. In [2], the control of the excitation of a SRG for maximum efficiency in the single pulse mode of operation has been presented. The turn-on/off angles are defined as control variables, the turn-on angle is set based on the output power, and the off angle is selected to achieve optimal efficiency under each power level and speed. Current chopping and single pulse control are adopted as an inner loop to retain the DC-link voltage in [10] and [11], respectively. Moreover, an optimal turn-on/off angle is chosen by an analysis of the system efficiency and torque ripple in [10]. While this occurs, the optimal turn-on/off angles are calculated by the ratio of two fluxes in [11]. One is the flux at the rotor position where the stator and rotor pole corners start to overlap, and the other one is the peak flux. In [12], the optimal turn-on/off angle, which corresponds to high system efficiency, is selected by measuring and analyzing the system losses of different reference powers and speeds. The control system in this paper is constituted by a PI power controller and a two-level current hysteresis controller. Based on a measured magnetization curve, the optimal turn-on/off angle can be obtained by analyzing the output power and system efficiency under a series of different on/off angles in [13]. In [14], under a fixed optimal turn-off angle, the generator output power is controlled by regulating the turn-on angle using fuzzy control. In [15], the author presents a novel switching strategy to 
increase the efficiency of a switched reluctance generator at low speeds. The asymmetric converter provides three switching states, and the proposed technique redistributes the three switching states within one working cycle. In [16], the control plan of variable-speed constant-voltage generation is designed for switched reluctance generators. In addition, the favorable dynamic and static characteristics of the switched reluctance generator system are verified by simulation results.

In this paper, the optimization of the efficiency of an SRG system over a wide speed range is the main objective. The current shape is the main key to optimizing the system efficiency. A modified angle position control method that can be used over a wide speed range is proposed based on the commonly-used control methods of SRGs.

\section{High EFFICIENCY CONTROL METHOD}

A switched reluctance machine operates in the generating mode, if each phase is excited after aligned position, where the phase inductance decreases, $\mathrm{d} L / \mathrm{d} \theta<0$. The torque is produced by the alignment tendency of the poles, and the electromagnetic torque of the SRG is the braking torque. When the SRG is excited, the voltage equation for each phase is given by:

$$
u_{p h}=R_{p h} i_{p h}+L\left(i_{p h}, \theta\right) \frac{d i_{p h}}{d t}+e_{p h}
$$

where, the subscript ph is one of these phases, $R_{p h}$ is the phase resistance, the phase inductance $\mathrm{L}$ is a function of the rotor position $\theta$ and the phase current $i_{p h}$, $e_{p h}=i_{p h} \omega_{r} \frac{\partial L\left(i_{p h}, \theta\right)}{\partial \theta}$ is the back-emf, and $\omega_{r}$ is the rotor speed.

The control parameters of the SRG are the phase voltage, the phase current, the switching on/off angle and so on. According to these control parameters, the commonly-used control methods can generally be divided into three types. They are the angle position control (APC), the soft chopping current control (SCCC), and the voltage chopping control (VCC) method.

\section{A. Angle Position Control Method}

The APC method is a method in which the phase current is controlled by adjusting the turn-on/off angle when the voltage which is added on the phase winding is constant. After this, the output power can be adjusted by the phase current. The turn-on angle $\theta_{o n}$ and the turn-off angle $\theta_{o f f}$ can be adjusted. As a result, the APC method can be further divided into three subtypes: 1) $\theta_{\text {on }}$ is fixed and $\theta_{\text {off }}$ is controlled, 2) $\theta_{o f f}$ is fixed and $\theta_{o n}$ is controlled, and 3) $\theta_{o n}$ and $\theta_{o f f}$ are fixed at the same time. Fig. 1 illustrates the effect of $\theta_{\text {on }}$

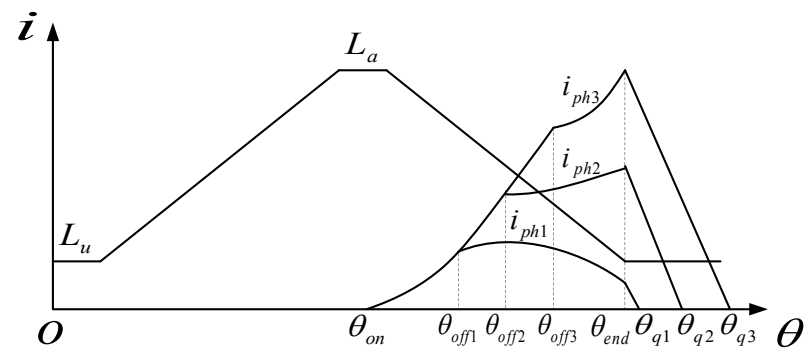

(a)

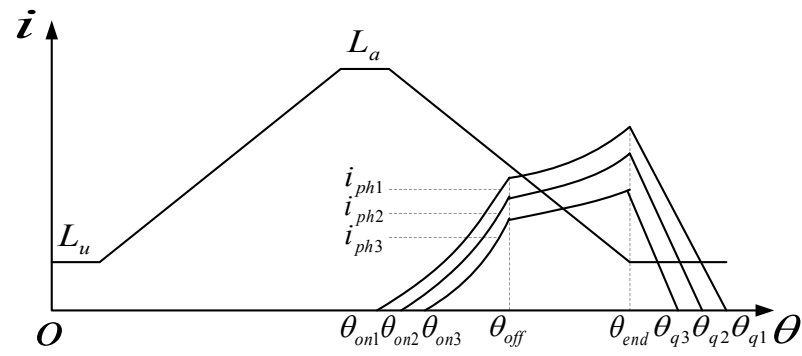

(b)

Fig. 1. Phase current under APC method. (a) $\theta_{o n}$ is fixed and $\theta_{\text {off }}$ is controlled. (b) $\theta_{\text {off }}$ is fixed and $\theta_{o n}$ is controlled.

and $\theta_{\text {off }}$ on the phase current.

The characteristics of the APC method are summarized as follows:

1. The torque adjustment range is wide.

2. Multiple phases can be conducted at the same time.

3. The optimal coupling of $\theta_{o n}$ and $\theta_{\text {off }}$ can improve efficiency.

\section{B. Soft Chopping Current Control Method}

The SCCC method consists of maintaining the winding terminal voltage constant, fixing $\theta_{o n}$ and $\theta_{\text {off }}$, and limiting the phase current value in a specific bandwidth by opening and closing the switching tubes on the upper and lower bridge leg of the power inverter. Using the SCCC method will avoid a sudden increase in phase current when the SRG is operated at a low speed.

The phase current under the SCCC method is shown in Fig. 2. In this figure, $I_{r e f}$ is the reference current, and $I_{\max }$ and $I_{\min }$ are the upper and lower limits of $I_{\text {ref }}$, respectively. In the excitation state, when $i_{p h}<I_{\text {min }}$, the switch is opened, and the phase current increases until $i_{p h}=I_{\max }$. On the other hand, when $i_{p h}>I_{\max }$, the switch is closed, and the phase current decreases until $i_{p h}=I_{\min }$.

In summary, the SCCC method has the following characteristics:

1. This method is suitable for the low speed and braking mode of operation.

2. The dynamic response to anti-load disturbance is slow. 
3. The current chopping frequency is not fixed. It varies with the band of the current error.

4. It is not good for the elimination of electromagnetic noise.

\section{Voltage Chopping Control Method}

Through the VCC method, the power inverter is switched to operate in the pulse width modulation (PWM) mode under constant $\theta_{o n}$ and $\theta_{\text {off }}$ conditions. The VCC method can be divided into two modes. One mode is based on adjusting the rms value of the excitation voltage by controlling the duty ratio of the PWM signal in the excitation state. The other is based on adjusting the rms value for the voltage generated by controlling the duty ratio of the PWM signal in the generation state.

Fig. 3 shows the phase current under the VCC method. From this figure, it can be seen that the frequency of the modulation pulse will affect the current shape.

The characteristics of the VCC method are summarized as follows:

1. This method has good controllability, and is suitable for the entire speed range.

2. The dynamic response to anti-load disturbance is fast.

3. This method increases the switching loss.

\section{Analysis of the Commonly-Used Control Method}

The basic characteristics of these control methods are illustrated in Fig. 4. For a specific SRG, under the maximum applied voltage and maximum allowable current condition, there exists a critical speed, which is the highest speed that can maintain the maximum torque. The critical speed is called the rated speed or the first critical speed (it is expressed by $\omega_{1}$ in Fig. 4). Under $\omega_{1}$, the SRG shows a constant torque characteristic. In the constant torque region, the SCCC or VCC method can be used to limit the phase current. The maximum value of the applied voltage is determined by the power converter, and the dwell angle cannot increase indefinitely. Therefore, under the maximum applied voltage and optimal turn-on/off angle condition, the highest speed which can achieve maximum power is called the second critical speed (it is expressed by $\omega_{2}$ in Fig. 4).

Between $\omega_{1}$ and $\omega_{2}$, the SR machine shows constant power characteristics, where the APC method can be used to obtain a constant power. If the speed exceeds $\omega_{2}$, the SRG shows the series characteristic.

Fig. 5 gives the application scopes of three commonly-used methods in detail. In Fig. 5, $\omega_{0}$ is the maximum speed of the starting point of the chopping method, $\omega_{\operatorname{Amin}}$ and $\omega_{C \max }$ are the minimum speed limit for the APC method and the maximum speed limit for the SCCC method, respectively. It is worth noting that, the actual speed for using the SCCC

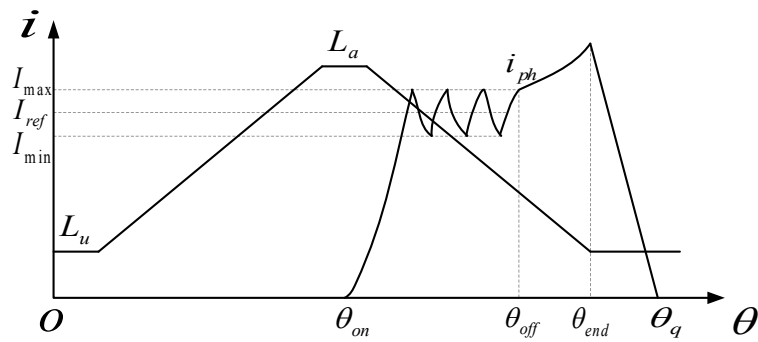

Fig. 2. Phase current under SCCC method

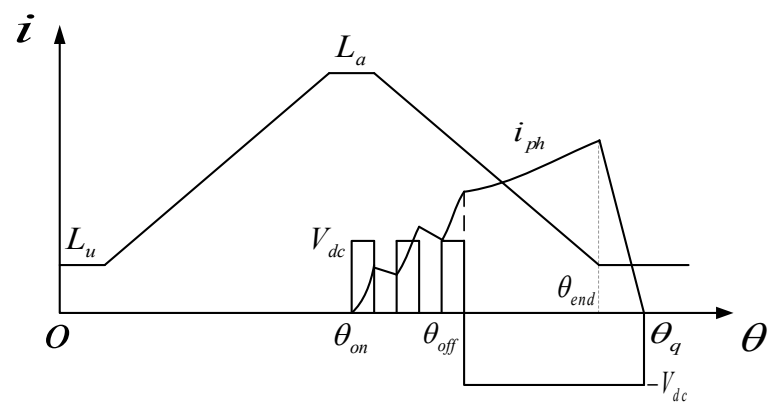

(a)

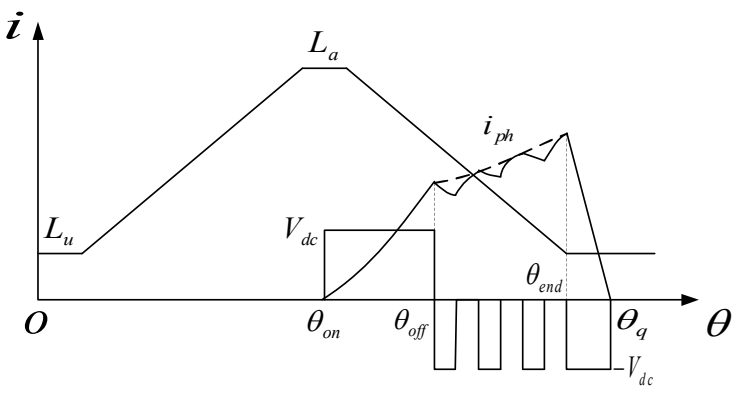

(b)

Fig. 3. Phase current under VCC method. (a) VCC for excitation voltage. (b) VCC for generation voltage.

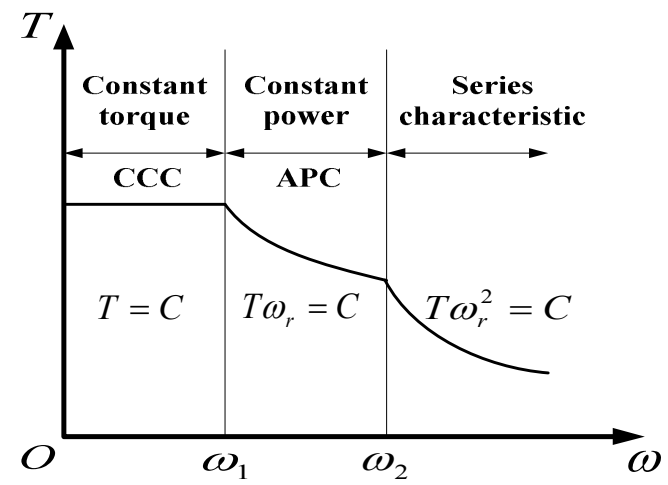

Fig. 4. Basic characteristics of SRG.

method is less than $\omega_{\text {Cmax }}$, and the actual speed for using the APC method is greater than $\omega_{\text {Amin }}$ in practical applications.

Fig. 6 is used to illustrate the calculation of $\omega_{\text {Amin }}$ and $\omega_{\text {Cmax }}$ easily. In this figure, $\theta_{1}$ is the rotor position where the leading-edge of the rotor salient pole overlaps with the stator salient pole. $\theta_{2}-\theta_{1}=\beta_{r}-\beta_{s}$, where $\beta_{r}$ and $\beta_{s}$ are the rotor pole arc and stator pole arc, respectively. Usually, 


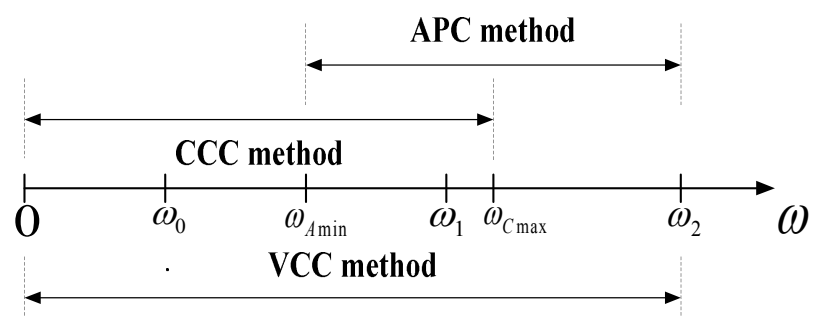

Fig. 5. Application scopes of control method.

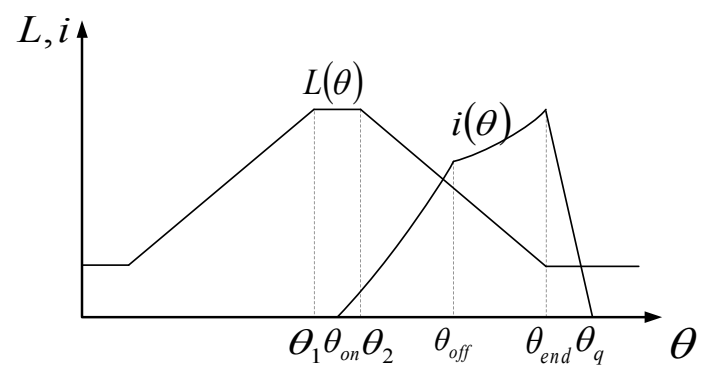

Fig. 6. Phase inductance and current of SRG.

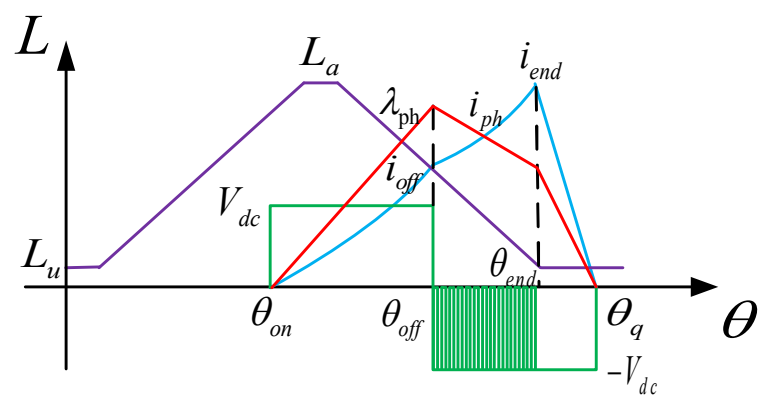

Fig. 7. Concept waveforms of MAPC method.

$\beta_{r}$ is bigger than $\beta_{s}$. In addition, $\theta_{\text {end }}$ and $\theta_{q}$ are the rotor positions where the stator and rotor pole corners complete overlap and the phase current extinguishes, respectively.

According to Fig. 6, if the maximum current value occurs on $\theta \quad\left(\theta_{2} \leq \theta \leq \theta_{\text {end }}\right)$, the current can be expressed by:

$$
i(\theta)=\frac{U_{S}}{\omega} \frac{2 \theta_{o f f}-\theta_{o n}-\theta}{L_{\max }-K\left(\theta-\theta_{2}\right)}
$$

where, $\quad K=\frac{L_{\max }-L_{\min }}{\beta_{s}}$. Therefore, if the allowable maximum current is $I_{H}, \omega_{\text {Cmax }}$ is;

$$
\omega_{C \max }=\frac{U_{S}}{I_{H}} \frac{2 \theta_{\text {off }}-\theta_{\text {on }}-\theta}{L_{\max }-K\left(\theta-\theta_{2}\right)}
$$

Considering the saturation effect, the maximum speed limit of the SCCC should be smaller than $\omega_{\text {Cmax }}$.

Under the APC method, the width of the winding current is narrow, the torque ripple is large, and the lower the speed, the higher the torque ripple. In the most severe cases, which are under the rated torque of the prime mover, the SRG speed decreases to 0 in the stepping angle range, and the speed at this time is $\omega_{\text {Amin }}$. According to the principle of energy conservation:

$$
\frac{1}{2} J \omega_{\text {Amin }}^{2}=T_{L} \frac{2 \pi}{m N_{r}}
$$

where, $T_{L}$ is rated torque of the prime mover. Thus, $\omega_{\text {Amin }}$ can be calculated by:

$$
\omega_{A \min }=\sqrt{\frac{4 \pi T_{L}}{m N_{r} J}}
$$

In order to ensure the reliable operation of the SRG, the minimum speed of the APC should be larger than $\omega_{\text {Amin }}$.

\section{E. Modified Angle Position Control Method}

In accordance with the commonly-used control methods, a modified angle position control (MAPC) method that can be used over a wide speed range is presented.

The MAPC method is a combination of the APC and the VCC methods. As such, it has the characteristics both of the APC and the VCC. From (1), it can be known that the behavior of the phase current depends on the relationship between the back-emf and the source voltage. In addition, the back-emf depends on the operation speed. Therefore, when the SRG is operated in a high speed range, the phase current increases after $\theta_{\text {off }}$. In this case, the MAPC method is the same as the conventional APC method, and it can be used to improve efficiency by adjusting $\theta_{o n}$ and $\theta_{\text {off }}$ to optimize the current shape. However, when the SRG is operated in a low speed range, the phase current can acquire three kinds of shapes by using some control methods, and the best current shape corresponds to the maximum efficiency. The MAPC method can be used to obtain the best current shape by controlling the PWM duty ratio and the value of $\theta_{\text {off }}$ which can influence the switch signal of the power converter. Accordingly, if the measured actual speed is lower than the rated speed, the voltage pulse can be applied after the $\theta_{\text {off }}$ position, and the current shape will be regulated by the PWM ratio.

The concept waveform of the MAPC method is shown in Fig. 7. From this figure, it can be seen that the essence of the MAPC method is to change the rms value of the source voltage in the generation stage. In addition, the $i_{\text {end }}$ and $i_{\text {off }}$ values can determine the current shape. It is worth noting that the MAPC can optimize the current by the turn on/off angle and the PWM ratio together. However, the VCC method usually regulates current through the PWM ratio under the constant turn on/off angle condition. Therefore, the MAPC is better suited to regulate current shape than the VCC method.

\section{PROPOSED CONTROL SCHEME}




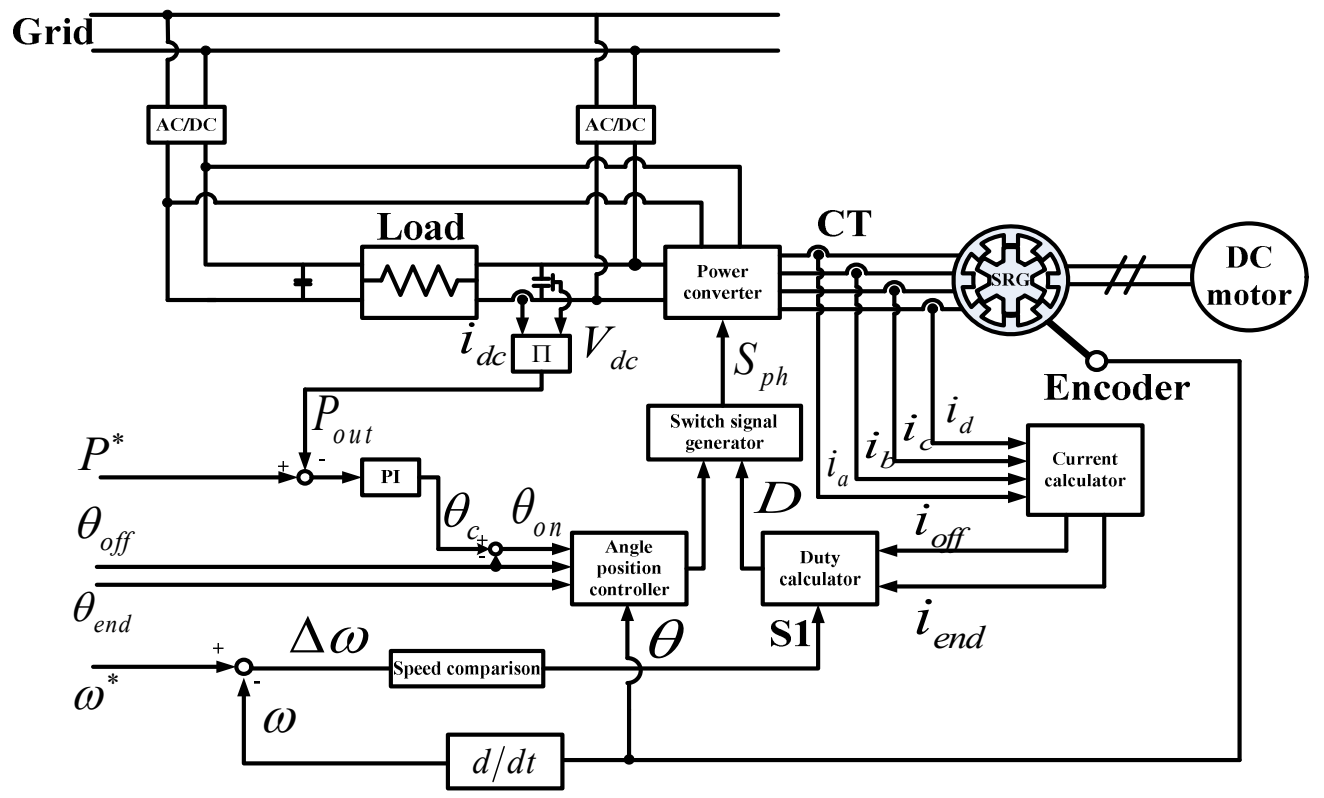

Fig. 8. Control scheme of 8/6 SRG system.

The proposed control scheme is shown in Fig. 8. It consists of a SRG, a load, a prime mover, a power converter, an angle position controller, a switch signal generator, a current calculator, and a position sensor. A DC motor as the prime mover provides the mechanical energy to the SRG, and the SRG delivers electrical energy to the load and grid.

In the figure, $P^{*}$ and $\omega^{*}$ are the command power and rated speed of the SRG, respectively. $P_{\text {out }}$ is the actual output power of the SRG.

It worth noting that, a "duty calculator" is used to adjust the source voltage in the generation stage, and it is determined by the difference between $i_{\text {end }}$ and $i_{\text {off }}$, and S1. $\mathrm{S} 1$ includes two signal values, and the signal values are dependent on the difference between $\omega^{*}$ and the actual angular speed $\omega$. When $S 1=0 \quad\left(\Delta \omega=\omega^{*}-\omega>0\right)$, the SRG is being operated under the rate speed condition.

The "angle position controller" has three input signals: $\theta_{\text {on }}, \theta_{\text {off }}$, and $\theta_{\text {end }}$. In this scheme, $\theta_{\text {on }}$ is calculated by $\theta_{\text {off }}$ and the dwell angle $\theta_{c} \cdot \theta_{c}$ is obtained by a PI controller, and the input signal of the PI controller is the difference between $P^{*}$ and $P_{\text {out }} . \theta_{\text {off }}$ in the scheme is fixed at a constant value. In addition, $\theta_{\text {end }}$ can be calculated by:

$$
\theta_{\text {end }}=\frac{\theta_{r r p}+\left(\beta_{s}+\beta_{r}\right)}{2}
$$

From (6), it can be found that, for a specified motor, the value of $\theta_{\text {end }}$ is fixed. According to the design parameters of the SRG which is used in this paper, $\theta_{\text {end }}=53.3^{\circ}$.

The power converter used in this control scheme is the

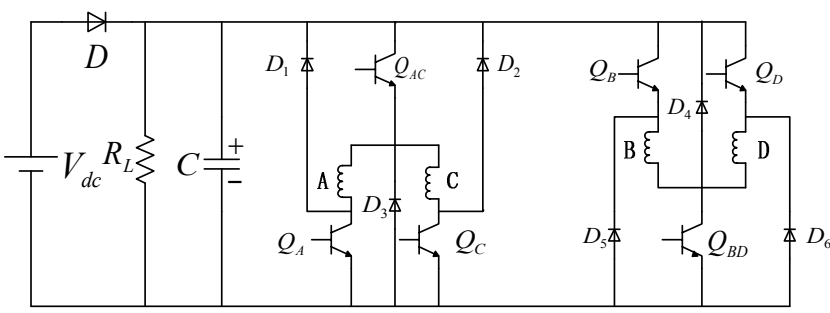

Fig. 9. Power converter of $8 / 6$ SRG.

share switch type, and the structure of the power converter is shown in Fig. 9. Fig. 10 takes phase $\mathrm{A}$ as an example to describe the operation mode of the converter. According to Fig. 9 and Fig. 10, the phase winding voltage value includes $V_{d c}, 0,-V_{d c}$ corresponding to the three operation modes of the converter.

\section{SIMULATION AND EXPERIMENTAL RESULTS}

The system efficiency can be calculated by:

$$
\eta=P_{\text {out }} / P_{M}
$$

where, $P_{M}=T_{e m} \omega=C_{T} \varphi I_{a} \omega$ is the input power of the DC motor. $C_{T}$ is the torque constant and $I_{a}$ is the armature current.

Fig. 11 gives the inductance profile of the SRG used in this paper.

Fig. 12 gives the simulation results of the relationship between the system efficiency and the current shape. The DC-link voltage is $150 \mathrm{~V}$, the speed is $1000 \mathrm{rpm}$, and $\theta_{\text {off }}$ and $\theta_{\text {end }}$ are fixed at $42^{\circ}$ and $53.3^{\circ}$ in the simulation. From these results, it can be known that the system is at its maximum when $i_{\text {off }}=i_{\text {end }}$. In other words, the flat-top 


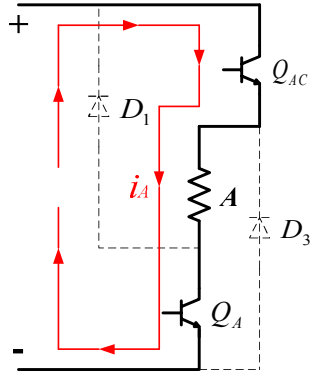

(a)

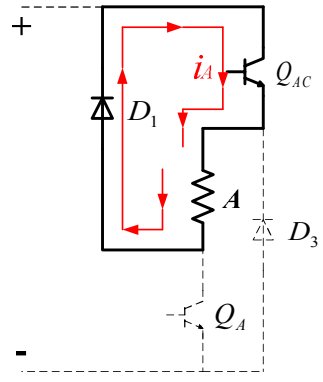

(b)

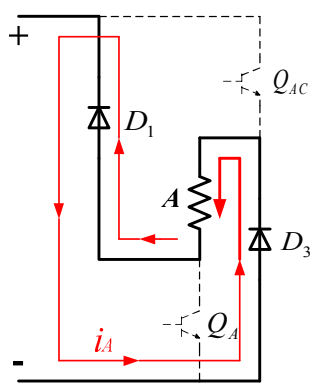

(c)

Fig. 10. Operation modes of converter. (a) Magnetization mode. (b) Freewheeling mode. (c) Demagnetization mode.

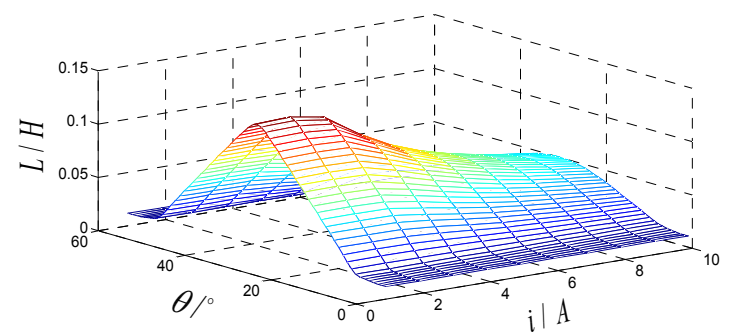

Fig. 11. Phase inductance versus phase current and rotor position.

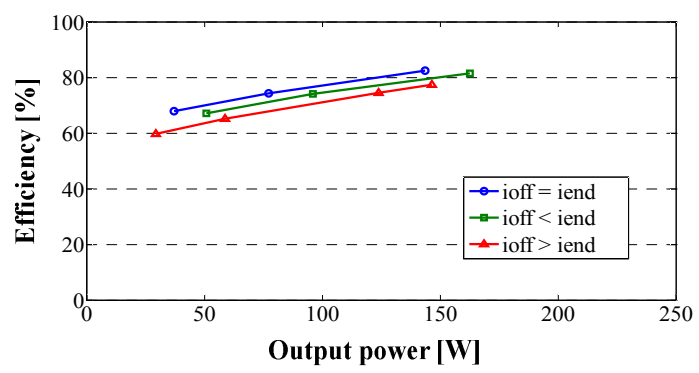

Fig. 12. Relationship between efficiency and current shape (simulation results).

current shape corresponds to the maximum efficiency.

In the control scheme, the strategy consists of optimizing $\theta_{\text {off }}$, and adjusting $\theta_{\text {on }}$ when the SRG is operated at a high speed. Fig. 13 gives the relationship between the efficiency and $\theta_{\text {off }}$. In the simulation, the source voltage is $150 \mathrm{~V}$, and the speed is $3000 \mathrm{rpm}$. Taking the selection range of $\theta_{o n}$ in the practical application consideration, $\theta_{\text {off }}$ is selected at $46^{\circ}$.

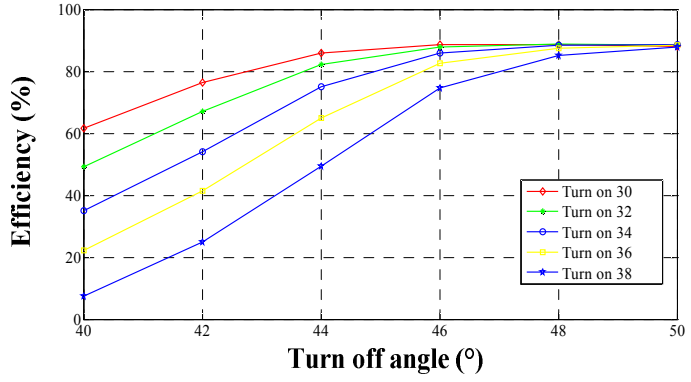

Fig. 13. Relationship between efficiency and $\theta_{\text {off }}$ (simulation results).

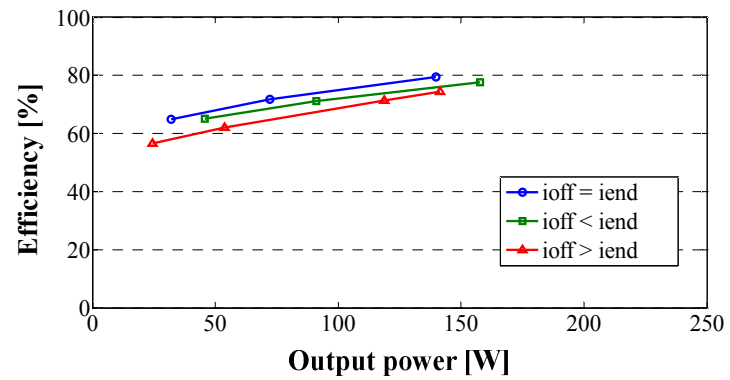

Fig. 14. Relationship between efficiency and current shape (experimental results).

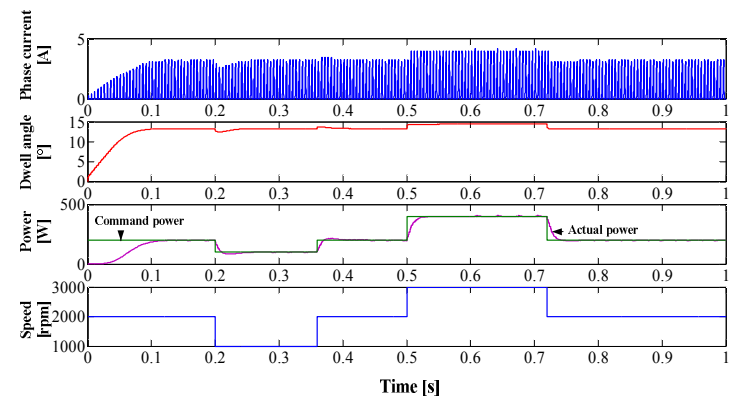

Fig. 15. Simulation result for variable speed conditions.

Fig. 14 gives the experimental results of the relationship between the efficiency and the current shape. In the experiment, the source voltage is $150 \mathrm{~V}$, and $\theta_{\text {off }}$ and $\theta_{\text {end }}$ are fixed at $42^{\circ}$ and $53.3^{\circ}$, respectively. From Fig. 14, it can be easily seen that, the system efficiency is at its maximum when $i_{\text {off }}=i_{\text {end }}$. In other words, at the same output power, the flat-top wave of the current corresponds to the maximum system efficiency when the SRG is operated under the rated speed. In addition, comparing the results of Fig. 12 and 14, it is not difficult to see that the results of Fig. 12 are larger than the results of Fig. 14 even though the conditions are the same. The reason is that only the copper and core losses are considered in the simulation. However, in the experiment, the switching loss and mechanical loss are also included.

Fig. 15 gives the simulation results for variable speed conditions. In the simulation conditions, the speed is changed ideally, and the optimal power command is altered according 


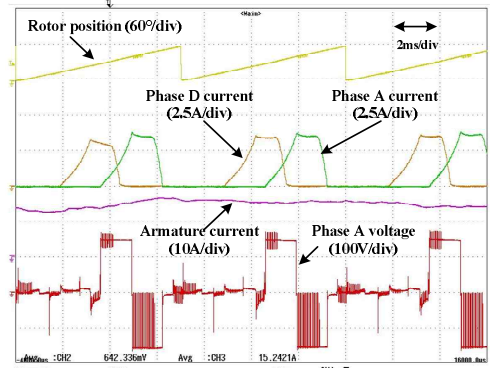

(a) $i_{\text {off }}=i_{\text {end }}$.

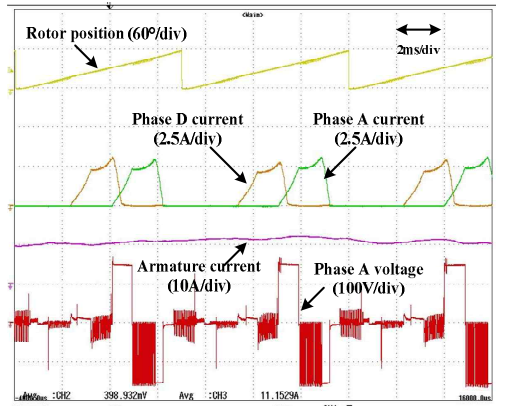

(b) $i_{\text {off }}<i_{\text {end }}$.

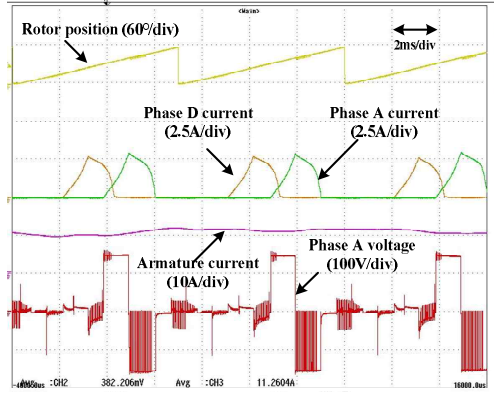

(c) $i_{\text {off }}>i_{\text {end }}$.

Fig. 16. Experimental waveforms at 1500rpm.

to the speed. The results indicate that the actual output power can be good for tracking variations in the command power, and that the dwell angle will be stabilized eventually. The control system is shown to haves good dynamic performance.

Fig. 16 gives the rotor position, phase current, and phase voltage of the three kinds of current shapes at $1500 \mathrm{rpm}$.

\section{CONCLUSIONS}

In this paper, optimization of the efficiency of the SRG over the whole speed range is investigated. The current shape is the key to improving efficiency. The advantages and disadvantages of the commonly-used control methods are discussed, and a MAPC method that can be used over a wide speed range is presented. Simulations and experiments are executed to verify the theoretical analysis. The results indicate that the flat-top current shape corresponds to the maximum efficiency when the output power is the same. The proposed control scheme has a good dynamic response, can be used over a wide speed range and is easy to accomplish.

\section{ACKNOWLEDGMENT}

This work was supported by the Ministry of Education (MOE) through BK21plus.

\section{REFERENCES}

[1] D. A. Torrey, "Switched reluctance generators and their control," IEEE Trans. Ind. Electron., Vol. 49, No. 1, pp. 3-14, Feb. 2002.

[2] Y. Sozer and D. A. Torrey, "Closed loop control of excitation parameters for high speed switched-reluctance generators," IEEE Trans. Power Electron., Vol. 19, No. 2, pp. 355-362, Mar. 2004.

[3] D. E. Cameron and J. H. Lang, "The control of high-speed variable-reluctance generators in electric power systems," IEEE Trans. Ind. Appl., Vol. 29, No. 6, pp. 1106-1109, Nov./Dec. 1993.

[4] A. Radun, "Generating with the switched reluctance motor," in Proc. the 9th IEEE Applied Power Electronics Conference and Exposition (APEC'94), Vol. 1, pp. 41-47, Feb. 1994.

[5] V. Nedic and T. A. Lipo, "Experimental verification of induced voltage self-excitation of a switched reluctance generator," in Proc. 35th IEEE Industry Applications Society Annual Meeting (IAS'00), Vol. 1, pp. 51-56, 2000.

[6] C. A. Ferreira, S. R. Jones, W.S. Heglund, and W. D. Jones, "Detailed design of a $30-\mathrm{kW}$ switched reluctance starter/generator system for a gas turbine engine application," IEEE Trans. Ind. Appl., Vol. 31, No. 3, pp. 553-561, May/Jun. 1995.

[7] R. Cardenas, W. F. Ray, and G. M. Asher, "Switched reluctance generators for wind energy applications," in Proc. IEEE Power Electronics Specialists Conference (PESC'95), Vol. 1, pp. 559-564, 1995.

[8] B. Fahimi, A. Emadi, and R. B. Sepe, "A switched reluctance machine-based starter/alternator for more electric cars," IEEE Trans. Energy Convers., Vol. 19, No. 1, pp. 116-124, Mar. 2004.

[9] E. Mese, Y. Sozer, J. M. Kokernak, and D. A. Torrey, "Optimal excitation of a high speed switched reluctance generator," in Proc. the 15th IEEE Applied Power Electronics Conference and Exposition (APEC'00), Vol. 1, pp. 362-368, 2000.

[10] C. Mademlis and I. Kioskeridis, "Optimizing performance in current-controlled switched reluctance generators," IEEE Trans. Energy Convers., Vol. 20, No. 3, pp. 556-565, Sep. 2005.

[11] I. Kioskeridis and C. Mademlis, "Optimal efficiency control of switched reluctance generators," IEEE Trans. Power Electron., Vol. 21, No. 4, pp. 1062-1072, Jul. 2006.

[12] Z. Li, D. Gao, and J.-W. Ahn, "Power closed-loop control of switched reluctance generator for high efficiency operation," Journal of International Conference on Electrical Machines and Systems, Vol. 1, No. 3, pp. 128-133, 2012.

[13] J. Faiz and R. Fazai, "Optimal excitation angles of a high speed switched reluctance generator by efficiency maximization," in Proc. the 12th Power Electronics and Motion Control Conference (EPE-PEMC'06), pp. 287-291, 2006.

[14] H. Chen and Z. Shao, "Turn-on angle control for switched reluctance wind power generator system," in Proc. 30th. Annu. Conf. IEEE Ind. Electron. Soc., pp. 2367-2370, 2004. 
[15] P. Kasmatin, D. Miljavec, and D. Voncina, "Increasing efficiency of the switched reluctance generator at low-speed operation," in Proc. the 8th Compatibility and Power Electronics Conference (CPE), pp, 197-202, 2013.

[16] Y. Chen, J. Sun, and S. Wang, "Switched reluctance generation control over wide speed range applied to flywheel energy storage system," in International Conference on Electrical Machines and Systems (ICEMS), pp. 1-5, 2011.

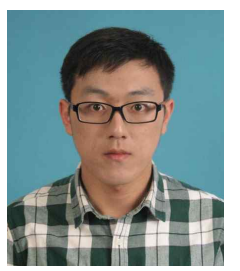

Siyang Yu was born in Liaoning, China, in 1988. He received his B.S. degree in Electrical Engineering from the Shenyang University of Technology, Shenyang, China, in 2011. He received his M.S. degree from both Kyungsung University, Busan, Korea, and the Shenyang University of Technology, in 2014. He is presently working toward his Ph.D. degree at the Institute of Electric Control Technology, Shenyang University of Technology. His current research interests include motor design and motor control systems.

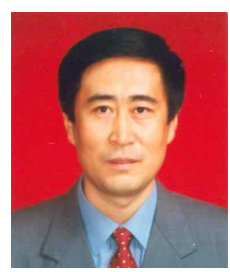

Fengge Zhang was born in Hebei, China, in 1963. He received his B.S., M.S., and Ph.D. degrees in Electrical Engineering from the Shenyang University of Technology, Shenyang, China, in 1984, 1990 and 2000, respectively. Dr. Zhang has been with the Shenyang University of Technology as a teacher in School of Electrical Engineering since 1984. His current research interests include new special motors and their control, renewable energy generation systems, electrical transmission and intelligent motor control.

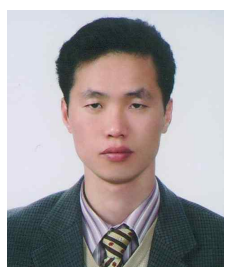

Dong-Hee Lee was born on November 11, 1970. He received his B.S., M.S., and Ph.D. degrees in Electrical Engineering from Busan National University, Busan, Korea, in 1996, 1998 , and 2001, respectively. He worked as a Senior Researcher of the Servo R\&D Team at OTIS-LG, Korea, from 2002 to 2005 . He has been with Kyungsung University, Busan, Korea, as an Assistant Professor in the Department of Mechatronics Engineering, since 2005. His current research interests include Power Electronics and motor control systems.

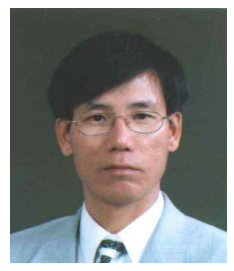

Jin-Woo Ahn was born in Busan, Korea, in 1958. He received his B.S., M.S., and Ph.D. degrees in Electrical Engineering from Busan National University, Busan, Korea, in 1984, 1986 and 1992, respectively. He has been with Kyungsung University, Busan, Korea, as a professor in the Department of Mechatronics Engineering, since 1992. He was a Visiting Professor in the Department of Electrical and Computer Engineering and in WEMPEC at the University of Wisconsin-Madison, Madison, WI, USA, from July 1998 to July 1999, and in the Department of Electrical and Computer Engineering at Virginia Tech, Blacksburg, VA, USA, from July 2006 to June 2007. Professor Ahn is an Adjunct Professor of the Shenyang University of Technology, Shenyang, China. He is the Director of the Smart Mechatronics Advanced Research and Technology Institute. He is the author of five books including $S R M$, the author of more than 200 papers and has more than 30 patents. His current research interests include advanced motor drive systems and electric vehicle drives. He has received many awards including a 2011 Busan Science and Technology Award. $\mathrm{He}$ also received a Ministerial Citation from the Ministry of Knowledge Economy and Ministry of Health and Welfare, Korea, for his contributions to electrical engineering and the industry. $\mathrm{He}$ served as a Conference Chairman of the International Conference on Electric Machines and Systems 2013 (ICEMS2013), and the International Conference on Industrial Technology 2014 (IEEE/ICIT2014). He is the Editor-in-Chief of the Journal of International Conference on Electric Machines and Systems (JICEMS). He is a Fellow Member of the Korean Institute of Electrical Engineers, a Member of the Korean Institute of Power Electronics, and a Senior Member of the IEEE. 